(c) American Dairy Science Association, 2007.

\title{
Predictive Modeling of Bacillus cereus Spores in Farm Tank Milk During Grazing and Housing Periods
}

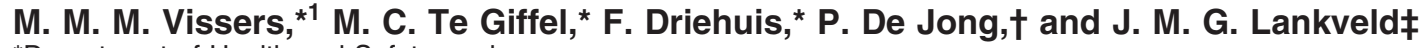 \\ ${ }^{*}$ Department of Health and Safety, and \\ †Department of Processing, NIZO Food Research, PO Box 20, 6710 BA Ede, the Netherlands \\ ‡Department of Dairy Science, Wageningen University and Research Centre, PO Box 8129, 6700 EV Wageningen, the Netherlands
}

\begin{abstract}
The shelf life of pasteurized dairy products depends partly on the concentration of Bacillus cereus spores in raw milk. Based on a translation of contamination pathways into chains of unit-operations, 2 simulation models were developed to quantitatively identify factors that have the greatest effect on the spore concentration in milk. In addition, the models can be used to determine the reduction in concentration that could be achieved via measures at the farm level. One model predicts the concentration when soil is the source of spores, most relevant during grazing of cows. The other model predicts the concentration when feed is the main source of spores, most relevant during housing of cows. It was estimated that when teats are contaminated with soil, $33 \%$ of the farm tank milk (FTM) contains more than $3 \log _{10}$ spores/L of milk. When feed is the main source, this is only $2 \%$. Based on the predicted spore concentrations in FTM, we calculated that the average spore concentration in raw milk stored at the dairy processor during the grazing period is $3.5 \log _{10}$ spores/L of milk and during the housing period is 2.1 $\log _{10}$ spores/L. It was estimated that during the grazing period a 99\% reduction could be achieved if all farms minimize the soil contamination of teats and teat cleaning is optimized. During housing, reduction of the concentration by $60 \%$ should be feasible by ensuring spore concentrations in feed below $3 \log _{10}$ spores/g and a $\mathrm{pH}$ of the ration offered to the cows below 5. Implementation of these measures at the farm level ensures that the concentration of $B$. cereus spores in raw milk never exceeds $3 \log _{10}$ spores/L.
\end{abstract}

Key words: Bacillus cereus, farm management, raw milk, modeling

\section{INTRODUCTION}

Growth of Bacillus cereus often limits the shelf life of pasteurized dairy products kept at refrigeration tem-

Received May 18, 2006.

Accepted August 9, 2006.

${ }^{1}$ Corresponding author: marc.vissers@nizo.nl peratures. Bacillus cereus in dairy products originates, at least partly, from the farm environment. The sporeforming properties of $B$. cereus enable the organism to survive pasteurization processes. In addition, recontamination during milk processing via (improperly cleaned) pasteurization equipment and during filling of the product can occur (Te Giffel et al., 1996; Lin et al., 1998; Svensson et al., 2000).

To prevent spoilage of pasteurized dairy products, $B$. cereus should be controlled by a chain management approach. It is important to reduce the concentration of spores of $B$. cereus in raw milk at the farm level or by bactofugation and to prevent recontamination and growth of $B$. cereus during processing. Of these aspects, least is known about the measures needed at the farm level to achieve a significant reduction and the quantitative effects of potential control measures at the farm level.

Raw milk in the silo tank at the site of dairy processors is a collection of a large number of farm tank milk (FTM) deliveries (up to 50 in the Netherlands). The concentration of $B$. cereus spores in the raw milk processed is the weighted average of the spore concentrations in the different FTM deliveries. Concentrations of $B$. cereus spores in FTM range from $<2 \log _{10}$ to 4.3 $\log _{10}$ spores/L. The highest concentrations occur at the end of summer and in early autumn (Te Giffel et al., 1995; Slaghuis et al., 1997). Raw milk before processing should always contain less than $3 \log _{10}$ spores/L (Walstra et al., 2005).

Farm tank milk is contaminated with spores of $B$. cereus via the exterior of the cow's teats and through improperly cleaned milking equipment (Griffiths and Phillips, 1990; Saran, 1995). A further increase in spore concentration could occur due to growth and sporulation of $B$. cereus during storage of the milk in the farm tank. Contamination via the exterior of teats occurs when teats are contaminated with dirt. During the grazing period, dirt attached to the teats mainly consists of soil. During housing, attached dirt predominantly consists of feces and bedding material (Christiansson et al., 1999). Dirt attached to the exterior of teats rinses off during milking. Subsequently, spores 


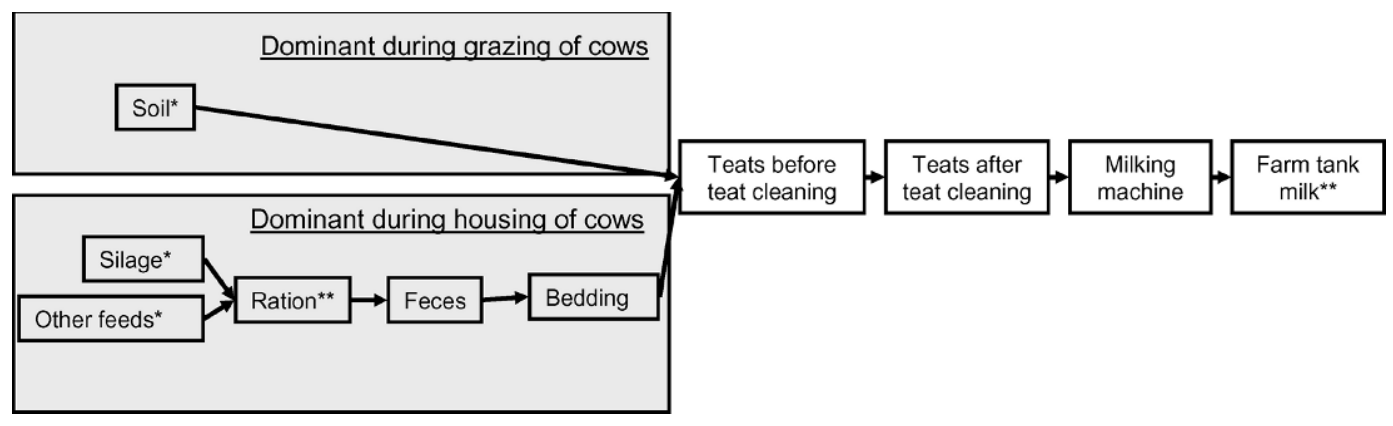

Figure 1. Contamination pathways for Bacillus cereus spores in farm tank milk; * = source of contamination, ** $=$ growth can occur within this carrier.

present in rinsed-off dirt contaminate the milk. The concentration of $B$. cereus spores transmitted to milk depends on the amount of dirt rinsed off the teats and the spore concentration in attached dirt.

Various measures, ranging from providing feeds of high (microbial) quality to thorough cleaning of teats before milking, potentially reduce the concentration of B. cereus spores in FTM. For efficient farm management it is important to identify the most effective measures to reduce the concentration of $B$. cereus spores in FTM. Based on the contamination pathway, Vissers et al. (2006) developed a simulation model to identify a strategy to control the concentration of butyric acid bacteria spores in FTM. The model contained interpretable and measurable variables and accounted for effects of uncontrollable variables. A control strategy was defined using Monte Carlo simulations.

In this study, a similar approach was applied to the contamination of FTM with B. cereus spores. The objectives of this study were to identify quantitatively factors that affect the concentration of $B$. cereus spores in FTM and to determine the reduction of the concentration that can be achieved via measures at the farm level. Based on this information a control strategy can be defined.

\section{MATERIALS AND METHODS}

\section{Model Development}

Model Assumptions. Based on the 2 contamination pathways (Figure 1), 2 simulation models were developed following the approach of Vissers et al. (2006). In the first model, soil was the only source of $B$. cereus and teats were only contaminated with soil (the soilbased model). During the grazing period teats are predominantly contaminated with soil (Christiansson et al., 1999) and therefore the soil-based model mostly corresponds to the contamination process during the grazing period. In the second model, feed is the only source and teats are solely contaminated with bedding (feed-based model). The feed-based model reflects the housing period. The following assumptions apply to the models developed: 1) Growth of B. cereus is possible in the silage-based ration provided to cows and in milk stored in the farm tank. Based on data of Te Giffel et al. (1995) and Slaghuis et al. (1997), no growth in bedding material was assumed; 2 ) When $B$. cereus can grow in the ration offered to the cows and in FTM the spore concentration increases at the same rate as the vegetative cells; 3) Lag time is assumed to be equal to 1 divided by the growth rate $(\mu)$. This is a common assumption in predictive microbiology (Zwietering et al., 1996); 5) The maximum attainable spore concentration in the feed ration $\left(C_{\text {ration, }} \propto\right.$, see Table 1$)$ is assumed to be 5 $\log _{10} / \mathrm{g}$. This value is slightly above the maximum concentration of $B$. cereus spores measured in animal feeds (Te Giffel, et al., 1995; Slaghuis et al., 1997; Christiansson et al., 1999); 6) The composition of the silage-based ration provided to cows is constant for the period of 6 milkings and is refreshed at constant intervals. Residence time in the gastrointestinal tract can be neglected when the composition of the ration is constant; 7) The cows are milked twice a day at a constant interval of $12 \mathrm{~h}$; 8) The milking equipment is cleaned properly and no contamination of the milk via the milking equipment occurs; 9) The concentration of B. cereus spores in the milk entering the farm tank $\left[C_{\text {milking }}\right.$ (spores/L)] is equal for all milkings collected in the farm tank; and 10) FTM is collected after 6 milkings. This is common practice in the Netherlands.

Model Structure. To have a measure of the hygiene status of pasture, cattle housing, and milking parlor, the herd is divided into 3 cow groups (slightly, moderately, and highly contaminated cows). The proportions of slightly, moderately, and highly contaminated cows represent the hygiene status. First, the concentration of B. cereus spores in the milk of each cow group $\left[C_{\text {cowgroup } y}\right.$ (spores/L)] is calculated using the equations in Table 


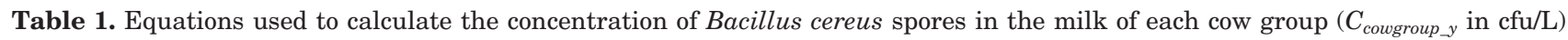

Intermediate concentration Equation

1. Concentration in the ration after mixing feed components $\left[C_{\text {ration }}(0) \text { in spores } / \mathrm{g}\right]^{1}$

$$
\begin{aligned}
& C_{\text {ration }}(0)=F_{\text {silage }} \cdot C_{\text {silage }}+\left(1-F_{\text {silage }}\right) \cdot C_{\text {otherfeed }} \\
& \left.\ln C_{\text {ration }}(t)\right)=\ln \left(C_{\text {ration }}(0)\right)+\mu \cdot A_{N}(t)-\ln \left(1+\frac{e^{\mu \cdot A_{N}(t)} \cdot t}{e^{\ln \left(C_{\infty} / C_{\text {ration }}(0)\right)}}\right) \\
& A_{N}(t)=\frac{1}{\mu} \ln \left(\frac{e^{-\mu \cdot t}+q_{0}}{1+q_{0}}\right) \text { with } q_{0}=\frac{2}{e^{\mu \cdot \lambda}-1} \\
& \mu=\gamma(T) \cdot \gamma(p H) \cdot \gamma\left(a_{w}\right) \cdot \mu_{\text {opt }} \text { with } \gamma(T)=\left(\frac{T_{\text {ration }}-T_{\min }}{T_{\text {opt }}-T_{\min }}\right)^{2}, \\
& \gamma(p H)=\left[\frac{\left(p H_{\text {ration }}-p H_{\min }\right) \cdot\left(p H_{\max }-p H_{\text {ration }}\right)}{\left(p H_{\text {opt }}-p H_{\min }\right) \cdot\left(p H_{\max }-p H_{\text {opt }}\right)}\right] \text { and } \gamma\left(a_{w}\right)=\frac{a_{w}-a_{w, \min }}{1-a_{w, \min }}
\end{aligned}
$$

2. Concentration in the ration at consumption, after growth $\left[C_{\text {ration }}(t) \text { in spores/g] }\right]^{2}$

3. Concentration in feces $\left(C_{\text {feces }}\right.$ in cfu/g) and bedding $\left(C_{\text {bedding }} \text { in spores/g }\right)^{3}$

$$
\begin{aligned}
& C_{\text {bedding }}=C_{\text {faeces }}=\left(\frac{1}{1-F_{\text {digested }}}\right) \cdot C_{\text {ration }} \\
& N_{\text {before }}=D M_{y} \cdot C_{\text {soil }} \text { or } N_{\text {before }}=D M_{y} \cdot C_{\text {bedding }} \\
& N_{\text {after }}=\left(1-T C_{\text {eff }}\right) \cdot N_{\text {before }} \\
& C_{\text {cowgroup }}=\frac{N_{\text {after }}}{Y_{\text {cow }}}
\end{aligned}
$$

4. Number attached to teats before teat cleaning $\left(N_{\text {before }} \text { in spores }\right)^{4}$

5. Number attached to teats after teat cleaning $\left(N_{\text {after }} \text { in spores }\right)^{5}$

6. Concentration in milk of each cow group per milking $\left(C_{\text {cowgroup }} \text { in spores/L }\right)^{6}$

${ }^{1} F_{\text {Silage }}(\%)$ is the fraction of silage in the ration, and $C_{\text {silage }}$ and $C_{\text {other feed }}$ are the concentrations of Bacillus cereus in fed silage and other feeds.

${ }^{2}$ The Baranyi growth model (Baranyi and Roberts, 1994) was used to simulate growth in the ration. Lag time $\lambda$ (in h) equals $1 / \mu$ and $t$ (h) is the time available for growth. Growth rate is estimated with the gamma concept of Zwietering et al. (1996).

${ }^{3} F_{\text {digested }}(\%)$ refers to the fraction of the feed ration that is digested.

${ }^{4} D M_{y}(\mathrm{~g})$ is the mass of dirt attached to the teats that will dilute in the milk without teat cleaning of the teats of cow group y. During the grazing period soil with concentration $C_{\text {soil }}$ (spores/g) attaches to the teats; during the housing bedding with concentration $C_{\text {bedding }}$ attaches to the teats.

${ }^{5}$ This equation is based on Chen et al. (2001). $T C_{\text {eff }}(\%)$ is the percentage of spores removed by the teat cleaning method applied.

${ }^{6} Y_{\text {cow }}$ is the average milk yield in liters.

1. Then, the concentration of spores in the milk entering the farm tank each milking $\left[C_{\text {milking }}\right.$ (spores/L)] is calculated as the weighted average of $C_{\text {cowgroup }}$ calculated for each cowgroup (based on the proportion of each cowgroup within the herd). The effect of growth of B. cereus in FTM is calculated using $C_{\text {milking }}$ and the equations in Table 2. The equations in Table 2 simulate the temperature of the FTM over time and the effects of this temperature profile and regular addition of $C_{\text {milking }}$ to the concentration of $B$. cereus spores in FTM transported to the site of the dairy processors $\left[C_{F T M}\right.$ (spores/L)].

Model Parameters and Variables. The model distinguishes model parameters, controllable variables, and uncontrollable variables. Variables are considered controllable when a farmer can directly influence the value of the variable via his/her management or when a farmer can measure the value of the variable and respond accordingly. Typical controllable variables are the temperature of the ration $\left[T_{\text {ration }}\left({ }^{\circ} \mathrm{C}\right)\right]$ and the teat cleaning method $\left(T C_{m t d}\right)$. Uncontrollable variables re- late to natural variability. A farmer cannot influence their value nor can the farmer adjust his/her management based on the values of the variables. Uncontrollable variables determine the range of FTM concentrations occurring under a specific combination of controllable variables. A typical uncontrollable variable is the concentration of $B$. cereus spores in soil.

Values for the model parameters were retrieved from published and unpublished data, from a survey involving 288 Dutch farmers, and from consultation of experts in the Dutch dairy industry. In the survey, farmers were sent a short questionnaire (20 questions) to collect basic farm management data, such as the size of the herd and teat cleaning methods used. The data set used to retrieve characteristics of the feed ration (e.g., $\mathrm{pH}$ and water activity) consisted of 241 records with various characteristics of grass and corn silages (Figure 2) and was collected by Blgg (Oosterbeek, the Netherlands). Blgg is a Dutch laboratory that determines characteristics (e.g., nutritional quality, composition, and $\mathrm{pH})$ of grass and corn silage. 
Table 2. Equations used to calculate the concentration of Bacillus cereus spores in farm tank milk $\left(C_{F T M}\right.$ in cfu/L)

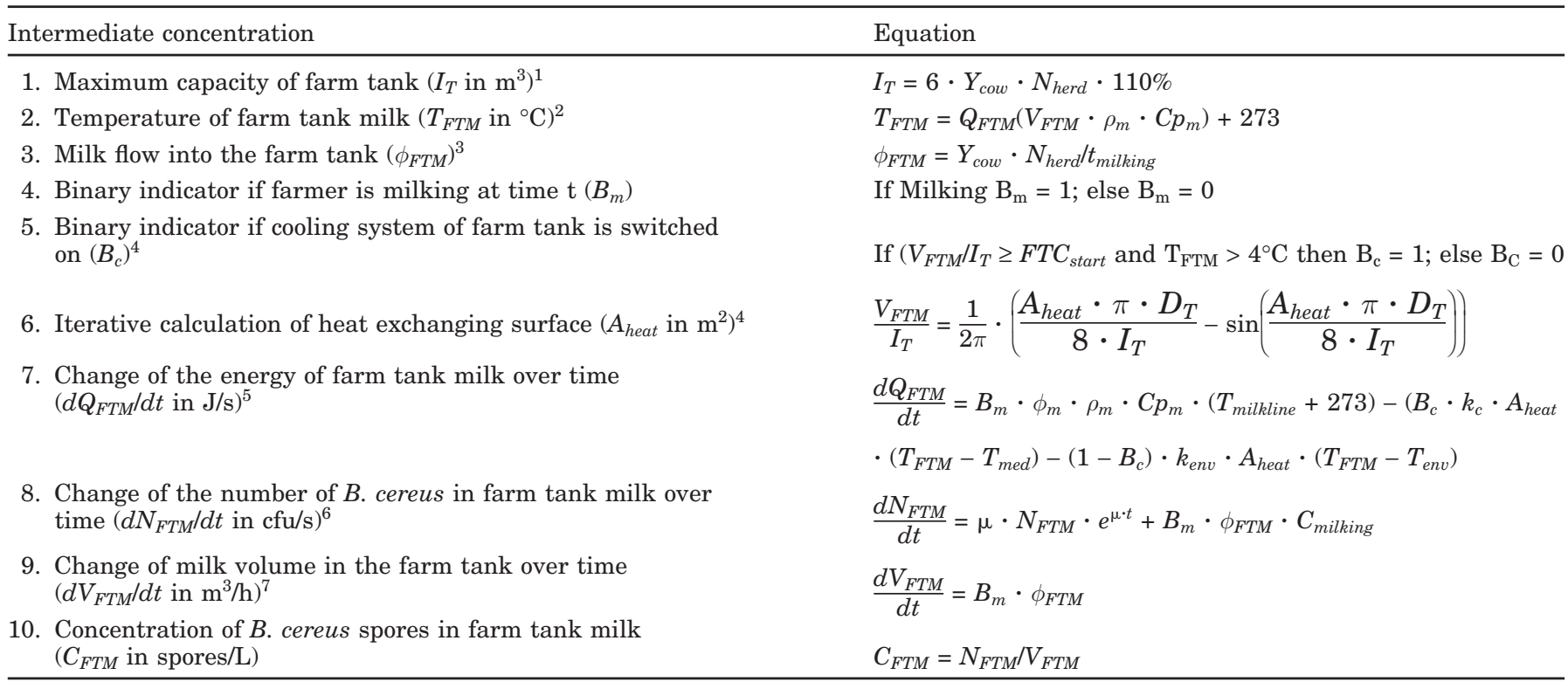

${ }^{1} Y_{\text {cow }}(\mathrm{L})$ is the milk yield per cow per milking, $N_{\text {herd }}$ is the number of lactating cows in the herd. Factor $110 \%$ is derived from NENISO5708 (ISO, 1983).

${ }^{2} \mathrm{Q}_{\mathrm{FTM}}$ is described with equation $7, \mathrm{~V}_{\mathrm{FTM}}(\mathrm{L})$ is the volume of milk in the farm tank, $\rho_{m}\left(\mathrm{~kg} / \mathrm{m}^{3}\right)$ is the density and $C p_{m}(\mathrm{~J} / \mathrm{kg} / \mathrm{K})$ is the heat capacity of milk.

${ }^{3}$ Variables $Y_{\text {cow }}$ and $N_{\text {herd }}$ are explained under footnote 1, and $t_{\text {milking }}(\mathrm{h})$ is the duration of one milking.

${ }^{4}{ }_{F T C}$ start $(\%)$ is the filling degree of the farm tank at the moment the cooling system of the farm tank starts. Other variables explained under equations 1 and 2 .

${ }^{5} D_{T}(\mathrm{~m})$ is the diameter of the farm tank and was obtained from www.meko.nl using the maximum capacity of the farm tank $\left[\mathrm{I}_{\mathrm{T}}\left(\mathrm{m}^{3}\right)\right.$, equation 1]

${ }^{6} \rho_{m}$ and $C p_{m}(\mathrm{~J} / \mathrm{kg} / \mathrm{K})$ are described under footnote $2, T_{\text {milkline }}\left({ }^{\circ} \mathrm{C}\right)$ is the temperature of the milk at the end of the milk line, $k_{c}\left(\mathrm{~W} / \mathrm{m}^{2} / \mathrm{K}\right)$ expresses the cooling capacity of the farm tank, $T_{\text {med }}\left(0^{\circ} \mathrm{C}\right)$ is the temperature of the cooling medium, $k_{\text {env }}\left(\mathrm{W} / \mathrm{m}^{2} / \mathrm{K}\right)$ is the heat resistance of the isolation of the farm tank and $T_{e n v}\left({ }^{\circ} \mathrm{C}\right)$ is the temperature in the milking parlor. All other variables are explained in equations 2,4 , 5 , and 6.

${ }^{7} \mu\left(\mathrm{h}^{-1}\right)$ is the growth rate of B. cereus at the applicable FTM temperature $\left(T_{F T M}\right.$ in $\left.{ }^{\circ} \mathrm{C}\right)$ and is calculated with the equations described in Table 2 (point 2 ), $\mathrm{t}$ is time in $\mathrm{s}$, and $C_{\text {milking }}$ (spores/L) in the concentration of $B$. cereus in the milk entering the farm tank. All other variables are explained in equations 3 and 4 .

Table 3 lists the controllable variables and the worst, average, and best values as encountered in the Netherlands. Worst and best refer to the direction of the effect of the variable on the $B$. cereus spore concentration in FTM (i.e., worst settings increase and best settings decrease the FTM spore concentration); average values correspond to the average values encountered in the Netherlands.

For model simulations, values for uncontrollable variables were preferably randomly sampled from an available data set to stay as close as possible to the actual variation occurring in practice. If no data set was available PERT distributions were used; PERT distributions are defined by minimum, most likely, and maximum values (values that can be obtained relative easily from the literature or experts). If the difference between the minimum and most likely value and the difference between the most likely and maximum value are equal, the shape of a PERT distribution is roughly similar to a normal distribution. Table 4 lists the uncontrollable variables and applicable datasets and statistical distributions. Table 5 lists the model parameters and their values.

\section{Model Simulations}

Both simulation models were programmed in Microsoft Excel (2002 version, Microsoft Corp., Redmond, WA). @Risk (2002 version, Palisade Corp, Newfield, NY) was used to perform Monte Carlo simulations using Latin Hypercube sampling. Each simulation comprised 2,500 iterations.

Model Validation. The simulation models can predict the concentration of $B$. cereus spores in FTM based on management information as inputs. Each calculation results in the prediction of a value for the concentration of B. cereus spores in FTM. However, in published surveys, farm management information is mini- 


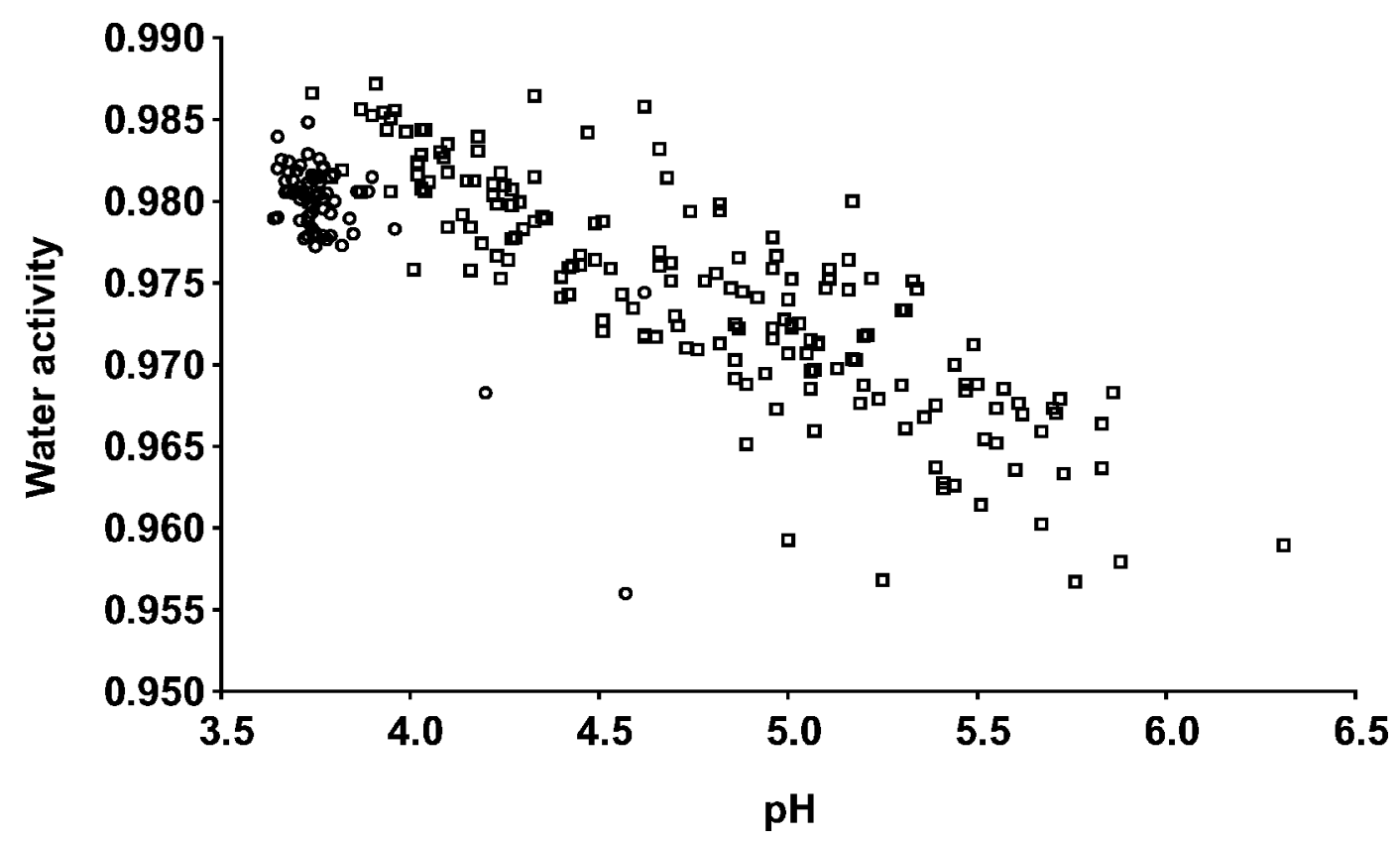

Figure 2. pH and water activity of grass $(\square)$ and corn $(\bigcirc)$ silages (Blgg, Oosterbeek, the Netherlands).

mal. Furthermore, concentrations of B. cereus spores in FTM were often below the detection limit and results are generally reported as the fraction of samples with a concentration below the detection limit (e.g., 97\% of the FTM during housing contained less than $2.3 \log _{10}$ spores/L; Slaghuis et al., 1997). In other words, no quantitative data are available. This complicated validation of the simulation models developed. Therefore, predicted cumulative probability distributions (CPD) were used to determine the validity of the models developed. The derived CPD describe the probability (between 0 and $100 \%$ ) that the concentration of B. cereus spores in FTM is below a concentration, $x$. For example, when a concentration of $2 \log _{10}$ spores/L corresponds to a predicted cumulative probability of $45 \%$, the simulation model predicted, in $45 \%$ of the cases, a concentration below $2 \log _{10}$ spores/L. In addition, the derived CPD give an indication of the range of concentrations occurring in practice and can be used to determine spore concentrations in raw milk stored at the dairy processor and in pasteurized milk.

For each model, a CPD was determined using Monte Carlo simulations. For each simulation, values for controllable variables were sampled from an available data set $\left(C_{\text {silage_a }}, C_{\text {other_feed_a }}, a_{w, \text { ration }}, p H_{\text {ration }}, t_{\text {refresh }}, P_{H C \text { coows }}\right.$, $T C_{m t d}$, and $T C_{\text {strat }}, F T C_{\text {start }}$, and $t_{\text {milking }}$; see Table 3) or from PERT distributions with the worst, average, and optimal values of Table 3 as distribution parameters $\left(F_{\text {silage }}, T_{\text {ration }}, P_{M C \text { cows }}, k_{c}, T_{\text {env }}\right.$, and $\left.T_{\text {milkline }}\right)$. The rationale for using a data set or PERT distribution was similar to the rationale for using a data set or PERT distributions for the uncontrollable variables. Values for uncontrollable variables were sampled from the datasets and distributions listed in Table 4. The derived CPD were compared with data of Te Giffel et al. (1995) and Slaghuis et al. (1997). In both these surveys, FTM concentrations were measured at Dutch experimental farms for a period of $1 \mathrm{yr}$.

Calculation of Concentration in Raw Milk Stored at the Dairy Processor. At the dairy processor, FTM of approximately 50 farms is mixed in a silo tank before further processing (Lankveld, 2002). The concentration in pasteurized milk depends on the concentration in the raw milk in the silo tank. Therefore, the spore concentrations in raw milk stored in the silo tank at the dairy processor during the grazing period (using data from the soil-based model) and housing period (using data from the feed-based model) were simulated using data derived for the model validations.

The concentrations in the silo tank were simulated using Monte Carlo simulations. It was assumed that milk of 50 farms is stored in 1 silo tank and that each farm produces the same volume of milk. For each iteration, 50 concentrations were randomly sampled from the data obtained in the validation study. The silo concentration is the average of the 50 sampled points. For both grazing and housing period, 2,500 iterations were performed.

Sensitivity Analysis. Worst- and best-case sensitivity analyses can be used to determine quantitatively 
Table 3. Controllable variables in the simulation models with worst, average, and best values as encountered in the Netherlands ${ }^{1}$

\begin{tabular}{|c|c|c|c|c|c|}
\hline Notation & Description & Worst & Average & Best & Reference \\
\hline$C_{\text {silage_a }}$ & Average concentration in silage $\left(\log _{10} \mathrm{cfu} / \mathrm{g}\right)$ & 4.5 & 2.0 & 0.0 & Slaghuis et al. (1997) \\
\hline$C_{\text {other feed_a }}$ & $\begin{array}{l}\text { Average concentration in all other feeds } \\
\text { besides silage }\left(\log _{10} \mathrm{cfu} / \mathrm{g}\right)\end{array}$ & 3.5 & 2.0 & 0.0 & Slaghuis et al. (1997) \\
\hline $\begin{array}{l}F_{\text {silage }} \\
\text { Feed management }\end{array}$ & Fraction silage in ration $(\%)$ & 90 & 65 & 50 & Survey of 288 Dutch farmers \\
\hline$a_{w, \text { ration }}$ & Water activity of feed ration ${ }^{2}$ & 0.99 & 0.98 & 0.95 & $\begin{array}{l}\mathrm{Blgg}^{3} \text { (Oosterbeek, The Netherlands, } \\
\text { 2003) }\end{array}$ \\
\hline$T_{\text {ration }}$ & Temperature of feed ration $\left({ }^{\circ} \mathrm{C}\right)$ & 37 & 20 & 10 & Expert Opinion (Vissers et al., 2006) \\
\hline$t_{\text {refresh }}$ & $\begin{array}{l}\text { Time between two feed ration } \\
\text { refreshments }(\mathrm{h})\end{array}$ & 120 & 24 & 6 & Survey of 288 Dutch farmers \\
\hline \multicolumn{6}{|l|}{ Hygiene } \\
\hline$P_{H C c o w s}$ & Proportion of highly contaminated cows (\%) & 10.0 & 2.0 & 0.0 & Survey of 288 Dutch farmers \\
\hline$P_{M C c o w s}$ & $\begin{array}{l}\text { Proportion of moderately contaminated } \\
\text { cows }(\%)\end{array}$ & 25.0 & 12.5 & 0.0 & Expert Opinion (Vissers et al., 2006) \\
\hline$T C_{\text {start }}$ & $\begin{array}{l}\text { Teat cleaning strategy }(0=\text { no teat cleaning; } \\
1=\text { only highly contaminated cows } \\
2=\text { highly }+ \text { moderately contaminated } \\
\text { cows; } 3=\text { all cows })\end{array}$ & 0 & 3 & 3 & Survey of 288 Dutch farmers \\
\hline \multicolumn{6}{|l|}{ Milking equipment } \\
\hline$F T C_{\text {start }}$ & $\begin{array}{l}\text { Filling degree of farm tank when cooling } \\
\text { starts }(\%)\end{array}$ & 15 & 15 & 4 & Survey of 288 Dutch farmers \\
\hline$k_{c}$ & Cooling capacity of farm tank $\left(\mathrm{W} / \mathrm{m}^{2} / \mathrm{K}\right)$ & 250 & 400 & 850 & $\begin{array}{l}\text { Survey of } 288 \text { Dutch farmers; } \\
\text { NEN-ISO } 5708 \text { (ISO, 1983) }\end{array}$ \\
\hline$t_{\text {milking }}$ & Duration of one milking $(\mathrm{h})$ & 2.0 & 1.5 & 1.0 & Survey of 288 Dutch farmers \\
\hline$T_{\text {env }}$ & Temperature in the milking parlor $\left({ }^{\circ} \mathrm{C}\right)$ & 25 & 15 & 5 & Expert opinion \\
\hline$T_{\text {milkline }}$ & Temperature at end of milk line $\left({ }^{\circ} \mathrm{C}\right)$ & 35 & 33 & 15 & Expert opinion \\
\hline
\end{tabular}

${ }^{1}$ The terms worst and best relate to the effect on the concentration of Bacillus cereus spores in farm tank milk. Variables are defined in accordance with defined main aspects of farm management (see Materials and Methods).

${ }^{2} \mathrm{pH}$ and water activity of the ration are correlated variables (correlation factor $=-0.83$; Figure 2 ).

${ }^{3} \mathrm{Blgg}$ is a Dutch laboratory that determines the characteristics of silages (e.g., composition and $\mathrm{pH}$ ).

the most important aspects affecting microbial contamination levels (Zwietering and van Gerwen, 2000). The impact of 5 major aspects of farm management on the concentrations of $B$. cereus spores in FTM was evaluated using worst- and best-case sensitivity analyses. The 5 aspects of farm management considered were: the initial feed quality, feed management (related to growth of $B$. cereus in the ration offered to the cows), hygiene, teat cleaning, and milking equipment functioning. These aspects apply to different parts of the contamination pathways of Figure 1 and comprise different controllable variables. In Table 3 , all controllable variables are grouped following the evaluated 5 aspects of farm management.

For each aspect, the worst-case sensitivity for aspect $\mathrm{x}\left(W C S_{x}\right)$ was calculated with equation 1 . In a similar way the best-case sensitivity was calculated. The worstand best-case sensitivities were calculated for the $95 \%$ percentile value of 2,500 simulated concentrations to identify aspects of farm management that affect the highest concentrations occurring.

$$
W C S_{x}=\log _{10}\left(\frac{C_{x}(\text { worst })}{C(\text { base })}\right)
$$

where $C_{x}$ (worst) $=95 \%$ percentile value of the FTM concentration when values of the controllable variables belonging to category $x$ are fixed at their worst value, and all other controllable variables are fixed at their average value; and $C$ (base) $=95 \%$ percentile value of the FTM concentrations when the values of all controllable variables are fixed at their average value.

For the soil-based model, worst- and best-case sensitivities were determined for the aspects hygiene, teat cleaning, and milking equipment. In addition, the sensitivity for the uncontrollable concentration of $B$. cereus spores in soil was determined to evaluate the importance of soil as a source of $B$. cereus spores. The worst and best values used for the concentration of $B$. cereus spores in soil were $6 \log _{10}$ and $1 \log _{10}$ spores/g, respectively. For the feed-based model, worst- and best-case sensitivities were determined for all 5 aspects of farm management. 
Table 4. Distributions applied to the uncontrollable variables in the simulation models

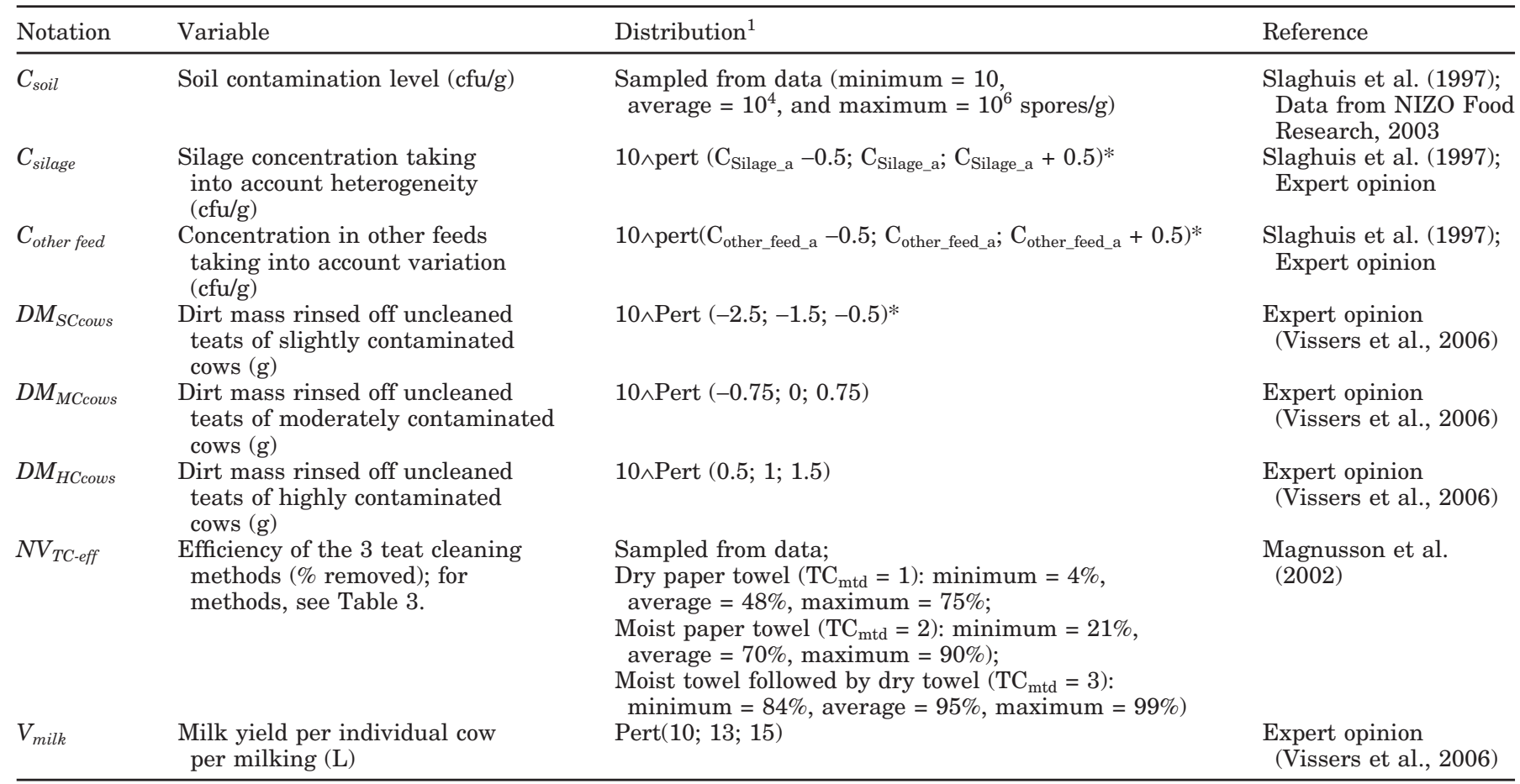

${ }^{1}$ Pert (minimum, most likely, maximum) specifies PERT distribution with minimum and maximum values as shown. The shape of the distribution is calculated from the most likely value. $10 \wedge$ Pert means 10 to the power pert.

\section{RESULTS}

\section{Model Validation}

To interpret model simulation results it is important to determine the validity of the models. This was done by determination of CPD of the concentration of $B$. cereus spores in FTM (see Figure 3). Besides the CPD derived with the soil- and feed-based models, survey data collected by Slaghuis et al. (1997) during the grazing and housing period are shown in Figure 3. Higher concentrations can be expected when teats are contami- nated with soil (solid line in Figure 3) than when teats are contaminated with feces and bedding (dashed line in Figure 3). When soil is the source of B. cereus spores, simulated spore concentrations in FTM were in $50 \%$ of the iterations below $2.1 \log _{10}$ spores/L and in $95 \%$ below $4.1 \log _{10}$ spores/L. Of the predicted concentrations with the soil-based model, $33 \%$ were above $3 \log _{10}$ spores/L. When feeds were the source of spores and spores were transferred to milk via feces and bedding, $50 \%$ of the simulated spore concentration in FTM was below 1.3 $\log _{10}$ spores/L and $95 \%$ of the simulated concentrations

Table 5. Model constants

\begin{tabular}{llcl}
\hline Notation & Description & Value & Reference \\
\hline$a_{w, \min }$ & Minimal water activity required for growth & 0.95 & Zwietering et al. (1996) \\
$C p_{m}$ & Heat capacity of milk (J/kg/K) & 4,180 & Walstra et al. (2005) \\
$C_{\infty}$ & Log $_{10}$ of maximum concentration of Bacillus cereus spores in & 5 & Slaghuis et al. (1997) \\
$k_{\text {env }}$ & the feed and ration $(\mathrm{cfu} / \mathrm{g})$ & 5 & NEN-ISO 5708 (ISO, 1983) \\
$N_{\text {herd }}$ & Heat resistance of the isolation of the farm tank $\left(\mathrm{W} / \mathrm{m}^{2} / \mathrm{K}\right)$ & 70 & Survey of 288 Dutch farmers \\
$p H_{\min }$ & Herd size (average in the Netherlands) & 4.9 & Zwietering et al. (1996) \\
$p H_{\text {max }}$ & Minimum pH required for growth & 8.1 & Zwietering et al. (1996) \\
$p H_{\text {opt }}$ & Maximum pH allowing growth & 6.5 & Zwietering et al. (1996) \\
$T_{\text {med }}$ & Optimum pH for growth & 0 & NEN-ISO 5708 (ISO, 1983) \\
$T_{\min }$ & Temperature of cooling medium in farm tank $\left({ }^{\circ} \mathrm{C}\right)$ & 0 & Zwietering et al. (1996) \\
$T_{\text {opt }}$ & Minimum growth temperature $\left({ }^{\circ} \mathrm{C}\right)$ & 37 & Zwietering et al. (1996) \\
$\mu_{\text {opt }}$ & Optimum growth temperature $\left({ }^{\circ} \mathrm{C}\right)$ & 2.0 & Zwietering et al. (1996) \\
$\rho_{m}$ & Growth rate under optimal conditions $\left(\mathrm{h}^{-1}\right)$ & 1,030 & Walstra et al. (2005) \\
\hline
\end{tabular}




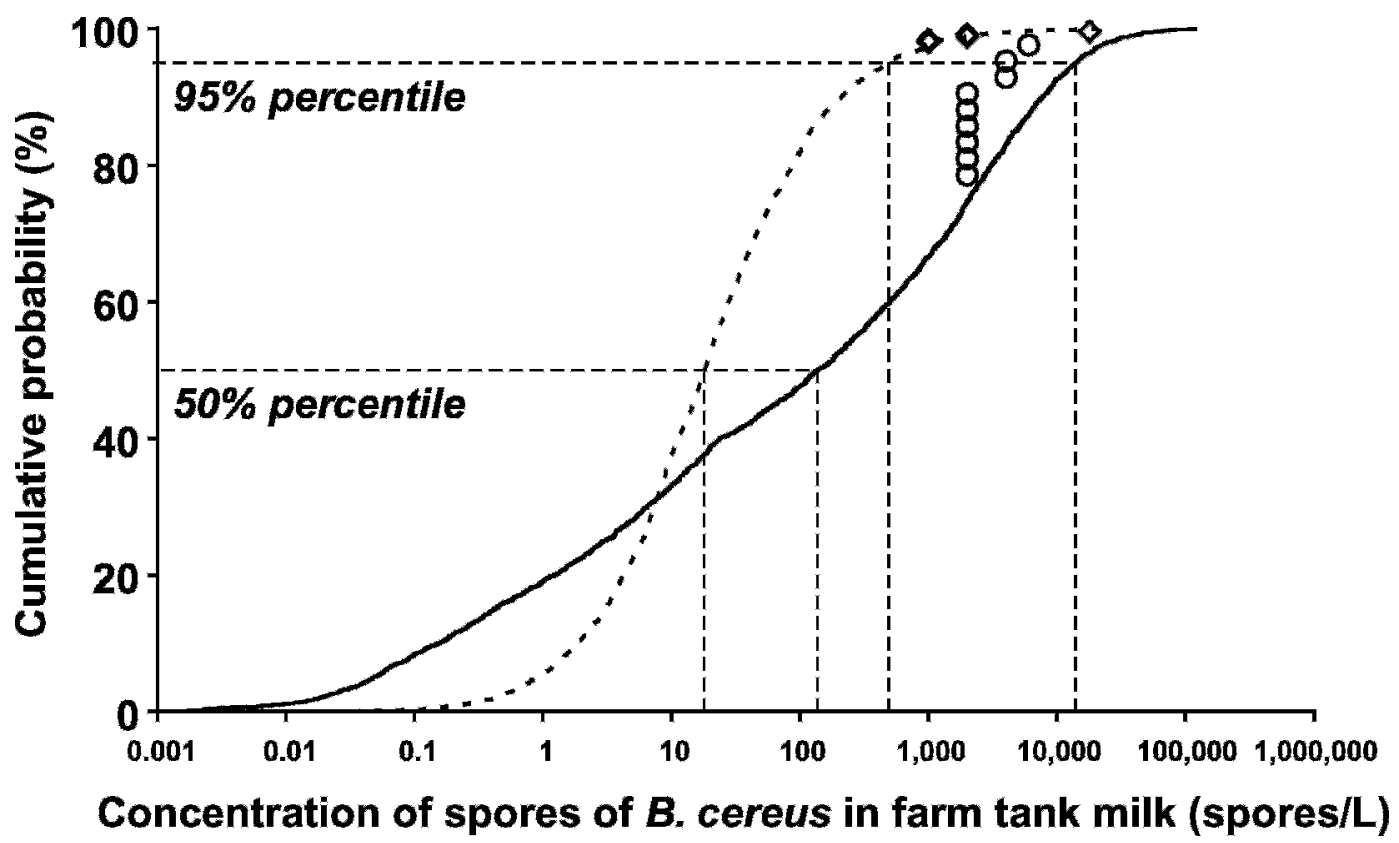

Figure 3. Simulated cumulative probability distributions of the concentration of Bacillus cereus spores in farm tank milk determined with the soil-based (solid line) and feed-based (dashed line) models. $\bigcirc$ indicate concentrations measured at farms with grazing cows; $\diamond$ indicate concentrations measured by at farms where cows were housed (Slaghuis et al., 1997); 50\% and 95\% percentiles are indicated.

was below $2.7 \log _{10}$ spores/L. Only $2 \%$ of the spore concentrations were above $3 \log _{10}$ spores/L. This implies that when the milking equipment is cleaned properly, concentrations above the defined maximum of $3 \log _{10}$ spores/L are most likely due to contamination of the teats with soil.

The CPD simulated with the soil-based model can be best compared with data acquired during grazing of cows, and the CPD derived with the feed-based model can be best compared with data acquired when cows are housed. The soil-based model predicts slightly higher concentrations of B. cereus spores in FTM than Slaghuis et al. (1997) measured during the grazing period (solid line vs. circles). The CPD derived with the feed-based model is in agreement with the data of Slaghuis et al. (1997) obtained at farms where cows were housed (dashed line vs. diamonds). In the survey of Te Giffel (1995) $36 \%$ ( $\pm 27 \%$ ) of the 250 -mL bulk tank milk samples tested positive for spores of $B$. cereus, but exact concentrations were not reported. Taking into account the lack of management information presented in these surveys, the limited number of farms sampled, and simplifications implicit in a model approach, it can be concluded that the model predictions are in line with concentrations observed in practice.

\section{Concentrations at the Dairy Processor}

The derived CPD of the concentration of B. cereus spores in FTM were used to calculate concentrations of
B. cereus spores in raw milk stored in collection tanks at the site of the dairy processors. This concentration is an important predictor for the spore concentration in pasteurized milk. The calculated average concentration of $B$. cereus spores in the silo tank at the dairy processor during the grazing period was $3.5 \log _{10}$ spores/ L. This implies that the concentration in raw milk during the grazing period is likely to be above the defined maximum (3 $\log _{10}$ spores/L).

The simulated average concentration for the housing period was $2.1 \log _{10}$ spores/L and the concentration was below $3 \log _{10}$ spores $/ \mathrm{L}$ in $99 \%$ of the iterations. Thus, during the housing period, the defined criterion of the dairy industry was generally met.

The calculated average concentrations in raw milk stored at the dairy processors are higher than the median concentration of the FTM in both periods $\left(2.1 \log _{10}\right.$ spores/L for the grazing period and $1.3 \log _{10}$ spores/ $\mathrm{L}$ for the housing period; Figure 3). This is because generally less than $15 \%$ of the FTM deliveries stored in one collection tank determine the concentration of $B$. cereus spores in the raw milk processed. In other words, a limited number of FTM deliveries (with the highest spore concentrations) determine the microbial quality of processed raw milk.

\section{Sensitivity Analysis}

Sensitivity analyses were performed at the $95 \%$ percentile values of the simulated concentrations during 

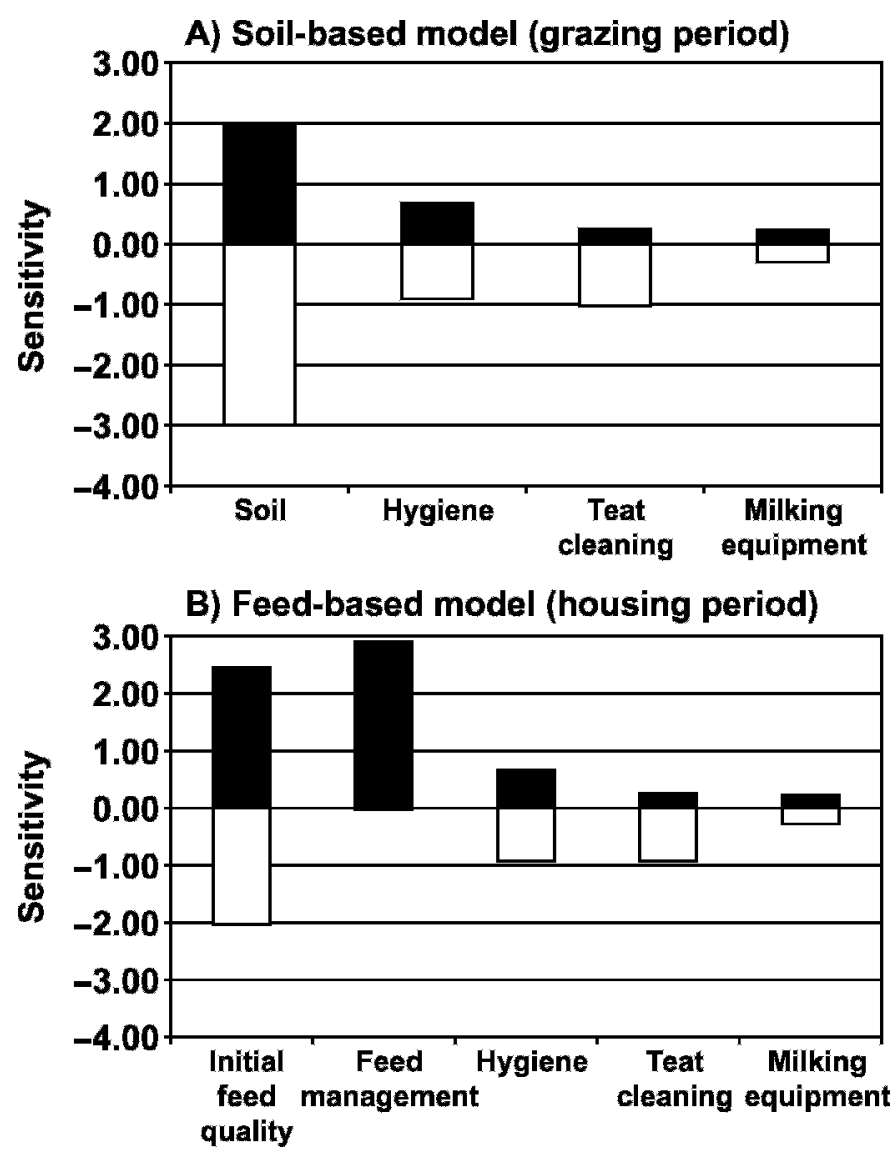

Figure 4. Worst case (black bar) and best case (white bar) sensitivities of the $95 \%$ percentile of the concentration of Bacillus cereus spores in farm tank milk for different aspects of farm management plus the soil concentration during A) grazing, and B) housing periods.

the grazing and housing period. The $95 \%$ percentile value simulated with the soil-based model under average settings of the controllable variables (base case) was $3.0 \log _{10}$ B. cereus spores/L. This implies that at an average farm during the grazing period the FTM is generally below $3 \log _{10}$ spores/L.

During the grazing period, the spore concentration in FTM mostly depends on the (uncontrollable) concentration of B. cereus spores in soil (Figure 4A). Decreasing the contamination of teats with soil (improved hygiene) reduces the spore concentration in FTM by approximately $1 \log _{10}$ spores/L compared with the base level. Cleaning the teats of all cows with a moist and a dry towel instead of cleaning with only a dry towel results in a similar reduction. Faster or slower cooling of the milk affects growth of $B$. cereus in FTM only marginally and is not expected to affect the FTM spore concentration.

The predicted $95 \%$ of the FTM spore concentration during the housing of the cows and with average set- tings of the controllable variables was $2.1 \log _{10}$ spores/ $\mathrm{L}, 0.9 \log _{10}$ lower than during the grazing period. The predicted concentration is most sensitive to the initial spore concentrations in the feeds (i.e., initial feed quality) and to feed management (Figure 4B). Feed management relates to growth of $B$. cereus in the ration offered to the cows. At an average farm, the $\mathrm{pH}$ of the ration (4.6) prevents an increase of the concentration of $B$. cereus in the ration (best-case sensitivity $=0 \log _{10}$ spores/L). However, when the $\mathrm{pH}$ of the ration increases above 5.0 and when the period between 2 feed ration refreshment is long ( $>24 \mathrm{~h}), B$. cereus could grow and the spore concentration in the ration could increase as indicated by the worst-case sensitivity for feed management (approximately $3 \log _{10} \mathrm{cfu} / \mathrm{L}$ ). Significant growth of $B$. cereus could occur when the $\mathrm{pH}$ of the ration is above 5.2 , temperature is above $20^{\circ} \mathrm{C}$, and feed is not refreshed daily.

A comparison of Figure $4 \mathrm{~A}$ and $4 \mathrm{~B}$ shows that the concentrations in the sources of contamination (soil and feed) are most important for the final spore concentration in FTM. The most important difference is that the spore concentration in soil is uncontrollable, whereas a farmer can influence the concentration in the feed, for example by making good silage. This is problematic because, compared with the base level, a reduced concentration of $B$. cereus spores in soil (best-case sensitivity of $\sim 4 \log _{10} \mathrm{cfu} / \mathrm{L}$ ) affects the FTM concentration more than do improvements of the initial feed quality (bestcase sensitivity of $\sim 2 \log _{10} \mathrm{cfu} / \mathrm{L}$ ). In addition, a high initial quality of the feeds could be completely negated if growth of $B$. cereus in the ration were possible. In contrast, bad hygiene and inefficient teat cleaning do not diminish the positive effect of a low concentration of $B$. cereus spores in soil.

\section{Identification of Control Strategies}

From Figure 3 it can be concluded that the highest concentrations of spores occur when teats are contaminated with soil and that 15\% of the FTM deliveries with the highest concentration determine the concentration of $B$. cereus spores in the raw milk in the collection tank at the dairy processor. Figure 4A shows that during grazing, when teats are contaminated with soil, the highest concentration can be reduced by optimizing (pasture and milking parlor) hygiene and optimal teat cleaning practices (i.e., cleaning with moist and dry towels). The solid line in Figure 5 shows the CPD of the FTM concentration when all farmers implement measures that minimize the contamination of teats with soil (approximately $-0.5 \log _{10} \mathrm{~g}$ of dirt attached to the teats of all cows before teat cleaning) and apply the most efficient teat cleaning methods (average reduction 


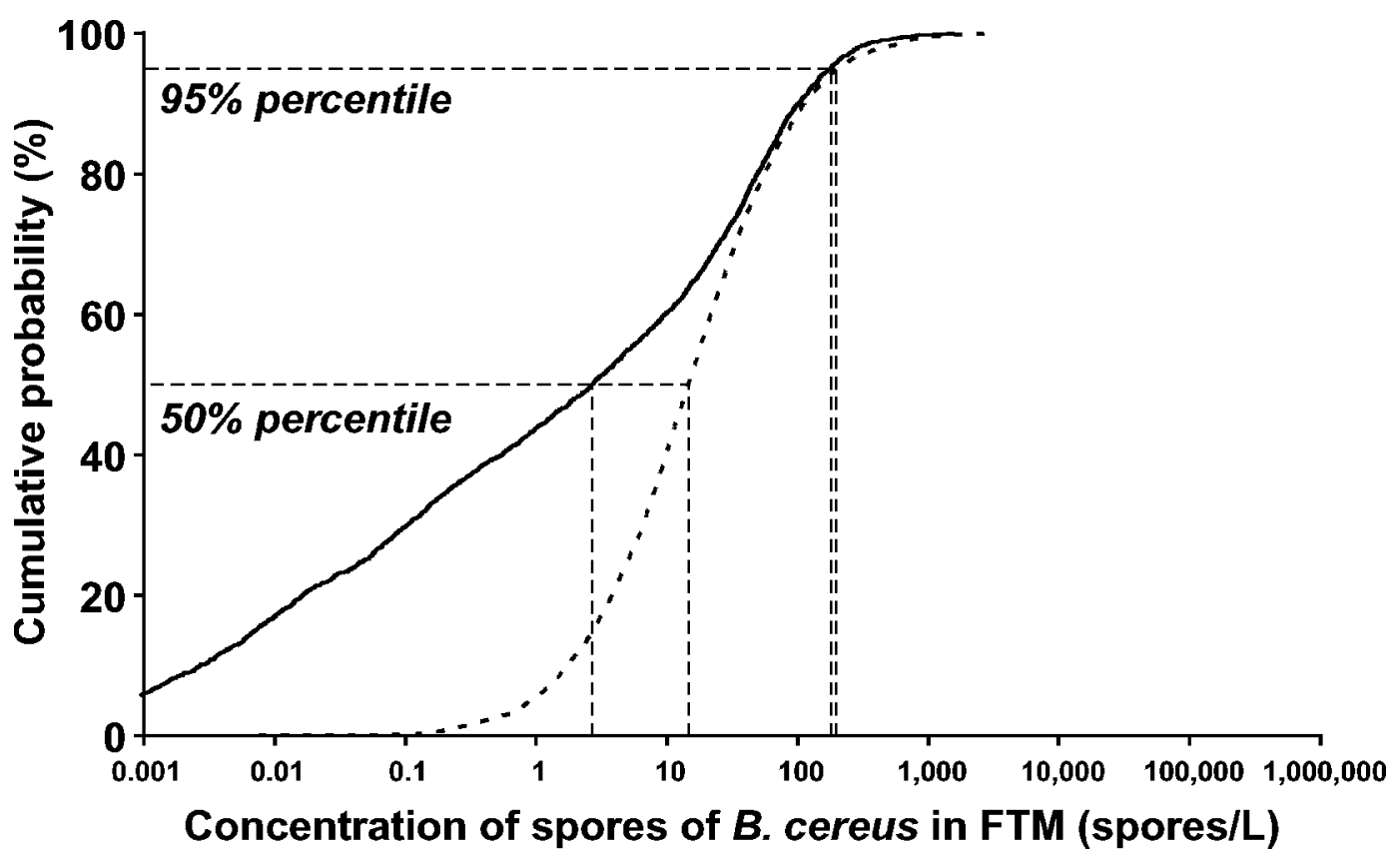

Figure 5. Simulated cumulative probability distributions of the concentration of Bacillus cereus spores in farm tank milk (FTM) determined with the soil-based model assuming optimal hygiene and teat cleaning practices (solid line) and with the feed-based model assuming a maximum initial contamination of the feeds of $3 \log _{10}$ spores/g and maximum ration $\mathrm{pH}$ of 5 (dotted line); $50 \%$ and $95 \%$ percentiles are indicated.

of $95 \%$ of the spores; see Tables 3 and 4 ). After implementation of these measures at all farms during the grazing period, the concentration of $B$. cereus spores in FTM will always be below $3 \log _{10}$ spores/L (Figure 5). It can be calculated that, after implementation of the suggested measures, the expected concentration in raw milk stored at the dairy processor will be $1.5 \log _{10}$ spores/L, a reduction of $99 \%$ compared with the base situation.

To obtain similar concentrations when teats are contaminated with feces and bedding, farmers should ensure that the feeds initially contain less than $3 \log _{10}$ spores/g and that the $\mathrm{pH}$ of the ration offered to the cows is below 5 . The dotted line in Figure 5 shows the predicted CPD when the requirements with respect to the initial feed quality and feed management are met. The predicted average concentration of $B$. cereus spores in raw milk stored at the site of the processors during the housing period is then $1.7(\sigma=0.2) \log _{10}$ spores/L, a reduction of $60 \%$ compared with the base situation.

\section{DISCUSSION}

Predictive models were developed to simulate the concentration of $B$. cereus spores in FTM. The aim was to evaluate different scenarios to determine the factors that have the greatest effect on the $B$. cereus spore concentration in FTM and to evaluate how FTM concen- trations could be reduced. In light of these objectives, the models developed were useful for this goal. Firstly, the sensitivity analyses revealed the most important factors affecting the spore concentration in FTM (spore concentration in soil and feeds, Figure 4). Secondly, strategies were identified that could reduce the spore concentration in raw milk stored at the dairy processor by $99 \%$ during the grazing period and by $60 \%$ during the housing period, respectively, compared with the base level.

\section{Control of Spore Concentration During the Grazing Period}

The simulations confirmed the conclusion of Christiansson et al. (1999) that, during the grazing period, the spore concentration in FTM is related to the contamination of teats with soil (Figure 3). Teats of grazing cows can also be contaminated with spores from feeds (via feces) but maximum spore concentrations in soil are higher than maximum spore concentrations in feces. Consequently during grazing, high $B$. cereus spore concentrations in FTM are most probably due to contamination of the teats with soil. With respect to control of the FTM concentration this is problematic because the spore concentration in soil is uncontrollable. Minimization of the contamination of teats with soil and optimization of teat cleaning efficiency at all farms in the 
Netherlands are necessary to achieve a $99 \%$ reduction of the spore concentration in raw milk and to ensure concentrations below $3 \log _{10}$ spores/L. It is important that all farms take the necessary measures because the concentration of $B$. cereus spores in processed milk is determined by less than $15 \%$ of the FTM deliveries. In practice, implementation of the necessary measures at all farms is likely to be difficult and an alternative strategy should be considered.

An alternative would be to house cows when the concentration of $B$. cereus spores in soil is too high. Farm tank milk will only contain more than $3 \log _{10}$ spores/L when the concentration in soil is above $4 \log _{10}$ spores/ g. Concentrations above $3 \log _{10}$ spores/L milk are rare and easier to achieve when cows are housed (Figures 3 and 5; Te Giffel et al., 1995; Slaghuis et al., 1997). However, farmers do not currently know the concentration of $B$. cereus spores in soil. Farmers can obtain information concerning the spore concentration in soil via regular sampling of soil and analysis of the samples for the $B$. cereus spore concentration. Another option is to identify factors that are indicators of high spore concentrations in soil and to develop a "soil concentration predictor." For example, Christiansson et al. (1999) detected a negative correlation between FTM concentrations and soil DM content. Based on this observation it could be beneficial to house cows only during damp and rainy days.

Bactofugation of raw milk during the grazing period is another alternative to reduce the concentration of $B$. cereus spores in milk. Bactofugation removes $\sim 98 \%$ of the spores (Te Giffel and Van der Horst, 2003), a similar reduction to that achieved via measures at the farm level. An economic evaluation should be performed to establish the most cost-effective control option: minimizing teat contamination and optimization of teat cleaning at all farms, moving cows inside when the $B$. cereus spore concentration in soil is above $4 \log _{10}$ spores/ $\mathrm{g}$, or bactofugation of raw milk at the dairy processor. In this economic evaluation, factors to include are the costs of communicating strategies to farmers, welfare costs of housing (relative to remaining on pasture), and practical aspects such as the frequency of moving cows in and outside.

\section{Control of Spore Concentration During the Housing Period}

If the milking equipment is cleaned properly, feeds are the main source of spores during housing of cows (Figure 3). Currently during the housing period, the concentration of spores of $B$. cereus in raw milk is almost always less than the defined maximum of $3 \log _{10}$ spores/ L (Te Giffel et al., 1995; Slaghuis et al., 1997; Figure 3).
However, simulations show that higher concentrations can occur when the initial concentration in the feeds is $>3 \log _{10}$ spores/g and when the spore concentration in the ration can increase due to growth of $B$. cereus (Figure 4B). To keep concentrations low, most attention should be paid to ensiled feeds because concentrations above $3 \log _{10}$ spores/g are found more frequently in silage than in other feeds. In addition, the $\mathrm{pH}$ of silage offered to the cows can increase to levels above 4.9 (at a $\mathrm{pH}$ below 4.9 growth of $B$. cereus is prevented). An increase in $\mathrm{pH}$ occurs when silage is exposed to air and yeasts start to grow and consume the preservative acids (Pahlow et al., 2003). However, high concentrations are also possible in other feeds; for example, Christiansson et al. (1999) measured an average of $3.5 \log _{10}$ spores/g with a maximum of $4.6 \log _{10}$ spores/g in hay. In feed concentrates, spore concentrations are almost always less than $3 \log _{10}$ spores/g and B. cereus spores in concentrates are generally mesophilic (Te Giffel et al., 1995; Slaghuis et al., 1997; Christiansson, et al., 1999).

\section{Accuracy of the Models Developed}

The validation (Figure 3 ) and additional simulations showed that the models developed were accurate and reliable. The assumptions made for model development did not affect the conclusions that were drawn from the simulations. An important assumption was made with regard to the increase of the spore concentration in the ration and FTM due to growth of $B$. cereus. It was assumed that the spore concentration increases at the same rate as the concentration of vegetative cells. Because sporulation requires time, this implies an overestimation of the increase of the spore concentration due to growth of $B$. cereus. However, no significant increase of $B$. cereus during storage of FTM was predicted. Consequently, the conclusion drawn with respect to the effect of improved cooling of the milk at the farm on the spore concentration in FTM (i.e., no positive effect on the concentration) is still valid. On the other hand, the feed-based model indicates that the spore concentration in the ration offered to the cows could increase significantly due to growth of $B$. cereus (see worst-case sensitivity bar for Feed Management in Figure 4B). It is possible that the concentration in the ration increases less than predicted but there are no data available to either support or reject the predicted increase. Therefore, to be on the safe side, recommendations should be based on an overestimation of the effect of growth. Nevertheless, it is recommended to perform experiments to quantify a possible increase over time of the spore concentration in the ration offered to the cows.

With respect to the accuracy of the model, it is important that the variable that required expert opinion 
to estimate variable values (because no data were available) has only a minor effect on the predicted FTM spore concentrations. If these variables had a large impact on the simulation results, conclusions drawn from the simulation would have been largely affected by judgments of experts.

\section{CONCLUSIONS}

The concentration of $B$. cereus spores in raw milk stored in collection tanks at the dairy processors is determined by a limited number of FTM deliveries (15\%) containing the highest concentration of spores. If milking installations were cleaned properly, the highest concentrations would occur during the grazing period when soil contains more than $4 \log _{10}$ spores/g. A concentration of $B$. cereus spores in FTM below $3 \log _{10}$ spores/L during the grazing period can be assured if the contamination of teats with soil is minimized and teat cleaning is optimized. Compared with the current situation in the Netherlands, implementation of these measures results in an approximately $99 \%$ reduction of the average concentration in raw milk during the grazing period. To ensure a concentration in FTM below $3 \log _{10}$ spores/L during the housing period, feeds should initially contain less than $3 \log _{10}$ spores/L and the $\mathrm{pH}$ of the ration should be below 5 . At most Dutch farms these requirements are met with respect to the initial contamination of the feeds and characteristics of ration.

\section{REFERENCES}

Baranyi, J., and T. A. Roberts. 1994. A dynamic approach to predicting bacterial growth in food. Int. J. Food Microbiol. 23:277-294.

Chen, Y., K. M. Jackson, F. P. Chea, and D. W. Schaffner. 2001. Quantification and variability analysis of bacterial cross-contamination rates in common food service tasks. J. Food Prot. 64:72-80.

Christiansson, A., J. Bertilsson, and B. Svensson. 1999. Bacillus cereus spores in raw milk: Factors affecting the contamination of milk during the grazing period. J. Dairy Sci. 82:305-314.
Griffiths, M. W., and J. D. Phillips. 1990. Incidence, source and some properties of psychrotrophic Bacillus found in raw and pasteurized milk. J. Soc. Dairy Technol. 43:62-66.

ISO (International Organization for Standardization). 1983. Refrigerated bulk milk tanks. Document no. 5708. ISO, Geneva, Switzerland.

Lankveld, J. M. G. 2002. Melk in de keten. Wageningen University, Wageningen, the Netherlands.

Lin, S., H. Schraft, J. A. Odumeru, and M. W. Griffiths. 1998. Identification of contamination sources of Bacillus cereus in pasteurized milk. Int. J. Food Microbiol. 43:159-171.

Magnusson, M., A. Christiansson, B. Svensson, and C. Kolstrup. 2002. Effect of different manual teat cleaning method on spores in milk. First North Am. Conf. Robotic Milking, Toronto, Canada. Wageningen Acad. Publ., Wageningen, the Netherlands.

Pahlow, G., R. E. Muck, F. Driehuis, S. J. W. H. Oude Elferink, and S. F. Spoelstra. 2003. Microbiology of ensiling. Pages 31-93 in Silage Science and Technology. D. R. Buxton, R. E. Muck, and J. H. Harrison, ed. Agronomy Monograph 42, Am. Soc. Agron. Inc., Crop Sci. Soc. Am. Inc., and Soil Sci. Soc. Am. Inc., Madison, WI.

Saran, A. 1995. Disinfection in the dairy parlour. Rev. - Off. Int. Epizoot. 14:207-224.

Slaghuis, B. A., M. C. Te Giffel, R. R. Beumer, and G. Andre. 1997. Effect of pasturing on the incidence of Bacillus cereus spores in raw milk. Int. Dairy J. 7:201-205.

Svensson, B., A. Eneroth, J. Brendehaug, G. Molin, and A. Christiansson. 2000. Involvement of a pasteurizer in the contamination of milk by Bacillus cereus in a commercial dairy plant. J. Dairy Res. 67:455-460.

Te Giffel, M. C., R. R. Beumer, M. H. Bonestroo, and F. M. Rombouts. 1996. Incidence and characterization of Bacillus cereus in two dairy processing plants. Neth. Milk Dairy J. 50:479-492.

Te Giffel, M. C., R. R. Beumer, B. A. Slaghuis, and F. M. Rombouts. 1995. Occurrence and characterization of (psychrotrophic) Bacillus cereus on farms in the Netherlands. Neth. Milk Dairy J. 49:125-138.

Te Giffel, M. C., and C. Van der Horst. 2003. Microfiltration under the microscope. Dairy Ind. Int. Oct:39-41.

Vissers, M. M. M., F. Driehuis, M. C. Te Giffel, P. De Jong, and J. M. G. Lankveld. 2006. Improving farm management by modeling the contamination of farm tank milk with butyric acid bacteria. J. Dairy Sci. 89:850-858.

Walstra, P., J. T. M. Wouters, and T. J. Geurts. 2005. Dairy Science and Technology. Taylor \& Francis, New York, NY.

Zwietering, M. H., and S. J. C. van Gerwen. 2000. Sensitivity analysis in quantitative microbial risk assessment. Int. J. Food Microbiol. 58:213-221.

Zwietering, M. H., J. C. d. Wit, and S. Notermans. 1996. Application of predictive microbiology to estimate the number of Bacillus cereus in pasteurised milk at the point of consumption. Int. J. Food Microbiol. 30:55-70. 